University of South Florida

DIGITAL COMMONS

Digital Commons @ University of

@ UNIVERSITY OF SOUTH FLORIDA

South Florida

School of Geosciences Faculty and Staff

Publications

School of Geosciences

1989

\title{
CASA Central and South America GPS Geodesy
}

James Kellogg

University of South Carolina

Timothy H. Dixon

California Institute of Technology, thd@usf.edu

R. Neilan

California Institute of Technology

Follow this and additional works at: https://digitalcommons.usf.edu/geo_facpub

Part of the Earth Sciences Commons

\section{Scholar Commons Citation}

Kellogg, James; Dixon, Timothy H.; and Neilan, R., "CASA Central and South America GPS Geodesy" (1989). School of Geosciences Faculty and Staff Publications. 518.

https://digitalcommons.usf.edu/geo_facpub/518

This Article is brought to you for free and open access by the School of Geosciences at Digital Commons @ University of South Florida. It has been accepted for inclusion in School of Geosciences Faculty and Staff Publications by an authorized administrator of Digital Commons @ University of South Florida. For more information, please contact digitalcommons@usf.edu. 


\section{CASA}

\section{Central and South America GPS Geodesy}

PAGES 649, 651, 655-656

James Kellogg

Department of Geological Sciences, University of South Carolina, Columbia

\section{Timothy Dixon and Ruth Neilan}

Jet Propulsion Laboratory, California Institute of Technology, Pasadena

\section{Introduction}

In January 1988, scientists from over 25 organizations in 13 countries and territories cooperated in the largest Global Positioning System (GPS) campaign in the world to date (Table 1) [Neilan et al., 1988]. From January 18 to February $5,1988,43$ GPS receivers collected about 590 station-days of data in American Samoa, Australia, Canada, Colombia, Costa Rica, Ecuador, New Zealand, Norway, Panama, Sweden, United States, West Germany, and Venezuela. The experiment was entitled CASA UNO, an acronym for Central and South America-and "uno" is Spanish for "one," designating first-epoch measurements. The CASA UNO experiment was the first civilian effort at implementing an extended GPS satellite-tracking network and established the first major GPS network in the northern Andean margin and the western Caribbean.

By coordinating observations with participating scientific institutions in Europe and the Americas, the number of scientifically interesting baseline measurements was increased, the overall solution improved, and experiment costs minimized. Geophysical and geodetic agencies in the various countries provided logistical support to ensure the success of the experiment. The agencies in Colombia, Costa Rica, Ecuador, Panama and Venezuela are interested in preserving the GPS network as a part of their permanent regional network and supplied geophysical personnel, field vehicles and naval vessel support.

One of the ultimate goals of the project is to measure strain in the northern Andes. On March 5, 1987, the need for strain measurements was tragically dramatized when a large earthquake $\left(\mathrm{m}_{\mathrm{b}}=6.8\right)$ on the fault system 80 $\mathrm{km}$ east of Quito, Ecuador, ruptured the trans-Andean oil pipeline and triggered land-

Cover. CASA UNO site locations of the first GPS network in the North Andes and Central America. Present-day plate motions (bold arrows) relative to the North Andean block (Cocos plate motion relative to Caribbean) showing average slip rates (in centimeters per year) during the last 5-10 m.y. after Minster and Jordan [1978]. See "Central and South America GPS Geodesy," by J. Kellogg, T. Dixon, and R. Neilan, p. 649.

slides and floods that killed over a thousand people. The epoch measurements of 1988 will be followed by measurements planned in 1990, providing first results on strain in the area. The repeat measurements will monitor convergence rates at the rapidly subducting Colombia $(6.4 \mathrm{~cm} / \mathrm{yr})$ and Middle America $(8$ $\mathrm{cm} / \mathrm{yr}$ ) trenches.

\section{TABLE 1. CASA UNO Participants}

Investigator

Ruth E. Neilan

James N. Kellogg

Timothy H. Dixon

James Stowell

Clemente Ropain U.

Sergio Camargo M., Benjamin Fernandez Ch. Hugh N. Caddess

Brian R. Tallman

Kenneth Barger,

Thomas Hughes,

Leonard Leos,

Vernon Perdue

Cesar Real R.

Luis Espin

J. Tejada

C. Vieto

J. Marino Protti Q.

Herman Drewes, Christopher Reigber,

K. Stuber,

H. Tremel

O. Chourio

Heinz Henneberg

Melvin Hoyer

S. Rekkedal

Bill Melbourne Gerald L. Mader Robert Schutz

Bob Russman

William H. Prescott,

George Williams

John Hannah

Roger Merrell

Russell Crooks

Jim Clynch

Josef Popelar

\section{GPS System Description}

The GPS is a satellite-based positioning system allowing centimeter level geodesy to be performed with low-cost portable receivers. Centimeter level precision has been demonstrated on baselines up to $2000 \mathrm{~km}$ in length [e.g., Beutler et al., 1987; Blewitt et al., 1988; Tralli and Dixon, 1988]. Such precise geodetic measurements will allow widespread determinations of plate motion rates within several years of measurements. Slower intraplate strain rates may be measurable over 5- to 10 year intervals. The NAVSTAR GPS satellites are administered by the U.S. Department of Defense, and published ephemerides transmitted by the satellites (the Broadcast Ephemerides) are accurate to a few parts in $10^{6}$. This is not adequate for high-precision geodesy on long baselines, but the ephemerides can be improved in post processing by employing the "fiducial concept." This approach utilizes simultaneous observation of the satellites at sites whose positions are well known, from Very Long Baseline Interferometry (VLBI) or Satellite Laser Ranging (SLR) stations. While the full system of satellites will

\section{Institutional Affiliation}

\section{Experiment Manager}

Jet Propulsion Laboratory/California Institute of Technology, Pasadena, Calif.

North Andes and Western Caribbean GPS Projects

University of South Carolina, Columbia, S.C.

Jet Propulsion Laboratory, Pasadena, Calif.

University NAVSTAR Consortium, Boulder, Colo.

Instituto Nacional de Investigaciones Geologico-Mineras, Bogota, Colombia

Instituto Geografico Agustin Codazzi, Bogota, Colombia

Inter-American Geodetic Survey, San Antonio, Tex. Defense Mapping Agency HTC/GSGS, Washington, D.C. Inter-American Geodetic Survey, Panama City, Panama San Jose, Costa Rica

Bogota, Colombia

Quito, Ecuador

Instituto Geografico Militar, Quito, Ecuador

Escuela Politecnica Nacional, Quito, Ecuador

Instituto Geografico Nacional Tommy Guardia, Panama City, Panama

Instituto Geografico Nacional, San Jose, Costa Rica

Universidad Nacional, Heredia, Costa Rica

Venezuelan Andes GPS Project

Deutsches Geodatisches Forschungsinstitut, Munich, West Germany

Direccion de Cartografia Nacional, Caracas, Venezuela La Universidad del Zulia, Maracaibo, Venezuela

Statens Kartverk, Honefoss, Norway

Extended Fiducial Network / Equipment Support

Jet Propulsion Laboratory, Pasadena, Calif

National Geodetic Survey, Rockville, Md.

Center for Space Research, Austin, Tex.

Defense Mapping Agency, Washington, D.C.

U.S. Geological Survey, Menlo Park, Calif.,

USGS, Reston, Va.

Department Surveys and Land Information, New Zealand

Texas Highway Department, Tex.

FAA, American Samoa

University of Texas at Arlington, Tex. EMR, Canada 
not become fully operational until 1992, geodetic-quality measurements can be made today using the present system configuration of seven operating satellites.

The current Block I GPS satellites orbit at an height of about $20,000 \mathrm{~km}$ in 12-hour orbits inclined at $63^{\circ}$ to the equator. Each satellite broadcasts on two L-band frequencies, carrier $\mathrm{L}_{1}$ at $1.57542 \mathrm{GHz}$ and carrier $\mathrm{L}_{2}$ at $1.2276 \mathrm{GHz}$. In order to correct for dispersive ionospheric effects, geodetic measurements involve dual frequency observations to determine carrier phase advance and may also use P-code pseudorange measurements to determine the group delay. The P-code is modulated on both carrier frequencies at $10.23 \mathrm{MHz}$.

Observations consist of simultaneous reception of multiple satellite signals at two or more ground stations. Four or more satellites are required to estimate user position and time. For relative positioning, data are differenced between satellites and ground station receivers to remove errors due to clock offsets and other common mode errors. Atmospheric calibration may be applied to correct the effects of variable nondispersive signal delay through the troposphere.

\section{Scientific Objectives}

High-quality geodetic data can yield important constraints on models of plate tectonic processes and behavior at convergent boundaries. For example, measurements along a convergent plate boundary could demonstrate whether the plate motion was episodic and associated with infrequent, large earthquakes. If transmission of such episodic motion is damped out by stress relaxation in a viscous asthenosphere [Bott and Dean, 1973; Berg et al., 1977], determination of the damp ing wavelength would constrain predictions of asthenosphere viscosity.

How much aseismic slip occurs along plate margins is a second important question that can be answered by precise geodetic measurements. The answer will be particularly relevant to understanding "seismic gaps" and aseismic (?) subduction such as the underthrusting beneath the North American continental margin in Washington and Oregon.

Intraplate deformation is a third basic problem that can be addressed by precise geodetic measurements. The assumption of plate rigidity is a first-order approximation that encounters many exceptions in large oceanic plates [Weissel et al., 1980; Stein and Okal, 1978] and continental plates. Deformation often appears to be distributed over broad zones, especially where plate boundaries involve continental crust Uordan, 1975; Dixon et al., 1985]. Strain may be spread continuously across a broad zone, or be confined to subparallel zones separated by more rigid microplates which may be rotating. Adequate characterization of such complex patterns of crustal strain is necessary for full understanding of the tectonic processes occurring at these boundaries, might aid in the difficult task of earthquake prediction, and may even allow quantification of the frictional forces that resist plate motion.
Precise geodetic measurements in the tectonically active North Andean margin (see cover) would provide valuable constraints on models for the three convergent boundary tectonic processes just discussed. Rapid subduction of Nazca oceanic crust beneath the North Andes [Minster and Jordan, 1978; Kel logg et al., 1985] is associated with episodic great shallow earthquakes [Pennington, 1981] Malpelo Island, located just seaward of the Colombia trench, about $390 \mathrm{~km}$ from the mainland, gives us the opportunity to directly measure Andean subduction rates for the first time. Similar data will accrue from Cocos Island to mainland Costa Rica. Second, the deformation of the most recent sediments in the South Caribbean and North Panama deformed belts suggests active aseismic underthrusting of Caribbean crust beneath the deformed belts [ $L u$ and McMillan, 1982; Lehner et al., 1983; Ladd et al., 1984]. A poorly defined Benioff Zone [Dewey, 1972; Pennington, 1981] has been interpreted as the result of slow subduction of Caribbean crust beneath the North Andes [Kellogg and Bonini, 1982]. Third, precise geodetic measurements in the North Andes would demonstrate whether strain is confined to the plate bound aries or distributed across a broad zone from the South Caribbean marginal fault to the East Andean fold belt [Jordan, 1975]

The North Andean geodetic field program and the subsequent analyses of the acquired data are directed toward completing the following objectives.

- To obtain critical baseline measurements between several Pacific islands on the Cocos and Nazca plates and Colombia and Middle America that, when compared with future observations, will monitor subduction rates across the trenches and spreading rates across the Galapagos Rise.

- Establish a survey network across the South Caribbean deformed belt that will demonstrate whether or not Caribbean crust is being subducted aseismically beneath the North Andes. If convergence is confirmed by reoccupation of the sites, we will be able to calculate the aseismic slip rate.

- Baseline measurements across the Romeral, Santa-Marta, and Bocono-East Andean fault systems will determine strain distribution across the North Andean continental margin. Although we predict that most of the strain is occurring at the Colombia Trench and South Caribbean deformed belt, we also predict that the attempted rapid subduction of the Carnegie Ridge, slow subduction of buoyant Caribbean crust, and the collision of Panama and the North Andes result in shear strain along the Romeral, Santa-Marta, and Bocono-East Andean fault systems at distances of up to $600 \mathrm{~km}$ from the margins

- To obtain elevation measurements to determine whether the northern Andes are still rising, as suggested by uplifted Pliocene-Quaternary terraces [Page and James, 1981] and first-order leveling [Luschen, 1983]. Although a 10-year interval may be necessary to measure regional uplift, crustal movements associated with large earthquakes, such as the December 12, $1979(\mathrm{M}=7.9)$ event near Tumaco, Colombia, would be immediately measurable [Luschen, 1983].

- Colocate Doppler and GPS to improve the frame tie between World Geodetic System (WGS) '72 and WGS ' 84 reference systems in this region.

\section{North Andes and Western Caribbean GPS Network Description}

The geometry of the North Andes-CASA UNO GPS network is shown on the cover. All 25 sites are marked by concrete monuments surrounded by several reference markers. The geodetic agencies of Colombia, Costa Rica, Ecuador, Panama, and Venezuela are currently surveying the sites into their national first-order geodetic networks. The initial network in Colombia consists of 13 sites: Bogota, Bucaramanga, Cali, Cartagena, La Palma (Buenaventura), Malpelo Island, Mocoa, Monteria, Pasto, San Andres Island, Tumaco, Valledupar, and Villavicencio. Three sites were observed in Costa Rica: Cocos Island, Liberia, and Limon. In Ecuador, three sites were observed: Baltra Island (Galapagos), Jerusalen (near Quito), and Quito. One site was occupied in Panama near Panama City. The initial network in Venezuela includes five sites: Barinas, El Batey, Merida, Por Fin, and Uribante.

One of the most exciting results anticipated after the second GPS occupation of these sites is the first direct measurement of the convergence rates across short baselines for rapidly subducting trenches. The predicted baseline shortenings of $6.4 \mathrm{~cm} / \mathrm{yr}$ at the Colombia trench and $8 \mathrm{~cm} / \mathrm{yr}$ at the Middle America trench are significantly larger than the 2- to $3-\mathrm{cm}$ level of accuracy predicted [Freymueller and Golombek, 1988]. Colombia trench-crossing baselines were measured from Malpelo Island to Tumaco $(390 \mathrm{~km})$, Cali $(570 \mathrm{~km})$, Pasto $(570 \mathrm{~km})$, and Quito, Ecuador $(580$ $\mathrm{km}$ ), and from Galapagos to Tumaco (1170 $\mathrm{km}$ ). Convergence rates across the Middle America trench will be measured from Cocos Island to Liberia $(540 \mathrm{~km})$, Limon $(620 \mathrm{~km})$, and Farfan $(870 \mathrm{~km})$

The controversial predictions of aseismic subduction of the Caribbean plate beneath the South Caribbean deformed belt will be tested with repeat GPS baseline measurements from San Andres Island to Cartagena $(710 \mathrm{~km})$ and Monteria, Colombia $(750 \mathrm{~km})$. The predicted shortening of $1.7+/-0.7$ $\mathrm{cm} / \mathrm{yr}$ should be detectable over a 3 - to 5-year interval.

Attempted subduction of the Carnegie Ridge and buoyant Caribbean crust and collision with Panama may be contributing to distributed shear strain within the North Andean microplate. Eight sites are positioned to measure strain along the Romeral-Cauca fault system: Quito, Tumaco, Pasto, La Palma, Cali, Monteria, Cartagena, and Valledupar. Convergent, divergent, or the predicted strike-slip displacement will be measured across baselines as short as $70 \mathrm{~km}$. Movement along the active Santa Marta-Bucaramanga fault will be monitored between Cartagena Valledupar, and Bucaramanga.

Offset Pleistocene glacial moraines and seismic slip rate estimates indicate that the North Andes microplate is slipping northeast relative to South America along the Bocono-East Andean frontal fault system at a rate of about $1.0+/-0.2 \mathrm{~cm} / \mathrm{yr}$ [Schubert, 1980; Aggarwal, 1983]. Baselines between the sites in Quito, Mocoa, Pasto, Bogota, Villavicencio, Por Fin, Uribante, El Batey, Merida, and Barinas were measured across the Bocono-East Andean frontal fault system. 


\section{Extended Fiducial Network Impact on Baseline Accuracy}

During the CASA UNO experiment, most of the GPS receivers were concentrated in Central and South America. During the time frame of the experiment, the visibility of the GPS satellites was limited and less favorable than in North America. Furthermore, the accuracies of the ephemerides degrade in the North Andes region due to the distance from satellite-tracking stations in North America. Therefore the predicted accuracies of baselines recovered for scientific interest in the region was about a factor of 2 worse than for similar baselines located in North America.

The concept of implementing an extended satellite-tracking network to supplement the CASA UNO campaign stems from results of covariance analyses performed by Freymueller et al. [1986], Wu et al. [1988] and Freymueller and Golombek [1988], using the OASIS/GIPSY software developed at the Jet Propulsion Laboratory, Pasadena, Calif. The covariance analysis performed by Freymueller et al. [1986] predicted a few parts in $10^{8}$ accuracies for baseline recovery in the North Andes region using the nominal four-station satellite-tracking network in the U.S. at three Polaris sites (Westford, Mass.; Ft. Davis, Tex.; and Richmond, Fla.) and Owens Valley Radio Observatory in California. The Wu et al. [1988] analysis found that using an extended network with stations located in Australia, Hawaii and New Zealand could improve GPS orbit accuracy by almost a factor of 3 over the four-station network in the U.S. Covariance analysis by Freymueller and Golombek [1988] suggested a significant improvement in accuracy for the CASA UNO baselines with the use of an extended tracking network.

These predictions led to the implementation of a network (Figure 1) that located GPS receivers at Black Birch Observatory, New Zealand; Pago Pago, American Samoa; Kokee Park, Hawaii; and at NASA's Deep Space Network (DSN) station in Canberra, Australia. These supplemented the NGS coordinated tracking stations in Richmond, Fla.; Westford, Mass.; and Mojave, Calif.; as well as Yellowknife, Canada; Tromso, Norway; Onsala, Sweden; and Wettzell, West Germany.

In choosing the final satellite observation schedule and determining the length of view periods needed for Central and South America, further covariance analysis was performed. A subset of 15 stations was chosen for the analysis, and it was assumed that carrier phase ( $1-\mathrm{cm}$ data quality) and pseudorange (200-cm data quality) were available at each site. Fiducial station errors were set at 4 $\mathrm{cm}$ in each component and treated as systematic (consider) errors in the analysis. Stations whose coordinates were estimated were Galapagos, Cocos, Malpelo, Buenaventura, Pasto, and Tumaco. These stations represent baseline lengths from 100 to $1000 \mathrm{~km}$. Two schedules were examined for the South American sites, with 7-hour and 9-hour observation periods.

The shorter schedule was expected to produce less accurate baselines; however, the longer schedule was considered to pose a risk to the integrity of the data since the demands on the field operators would be severe for a 3 -week experiment. Figure 2 plots the averaged standard deviations of the baseline com- ponents for baselines between the various sites. With either approach, the horizontal errors are $1-2 \mathrm{~cm}$ and the vertical error is about $3 \mathrm{~cm}$. Due to the benefit expected with the longer period, it was decided to use a 9hour schedule for the first session and then a 7.5-hour for the last two sessions of CASA UNO.

\section{Field Campaign}

The North Andes GPS epoch measurements were divided into three 5-day sessions. The Pacific coast of northwestern Colombia has one of the highest precipitation rates in the hemisphere, so it was essential that GPS measurements be made during the dry season from December through February to reduce the uncertainties attributable to atmospheric water vapor. Receivers at the sites on Malpelo Island, Panama, and Costa Rica remained fixed for all three sessions. During the first session from January 18 to 22,9 - hour observations were made in Jerusalem (near Quito), Tumaco, Pasto, Mocoa, La Palma, and Cali, as well as at the fixed sites. In the second session from January 25 to 29 , 7.5-hour observations were made at the fixed sites and at Galapagos, Jerusalen, Tumaco, Cali, Bogota, Villavicencio, and Bucaramanga. In the third session, February 1 to $5,7.5$ hour measurements were made at the fixed sites and Quito, Bogota, San Andres Island, Monteria, Cartagena, Bucaramanga, and Valledupar. The five Venezuelan sites were observed in four 2-day and two 3-day discontinuous 6-hour sessions.

About 212 days of GPS data were collected with 16 TI-4100 receivers in the North Andes and Central America. Incredibly, only 2 days of data were lost due to receiver failure. A D-series Water Vapor Radiometer (WVR) recorded data for 3 days at Tumaco prior to failure in heavy rain. Two D-series WVR's in Liberia and Limon, Costa Rica and one R-series WVR in Panama collected data for 19 days during the experiment. An additional 378 days of GPS data were collected with 25

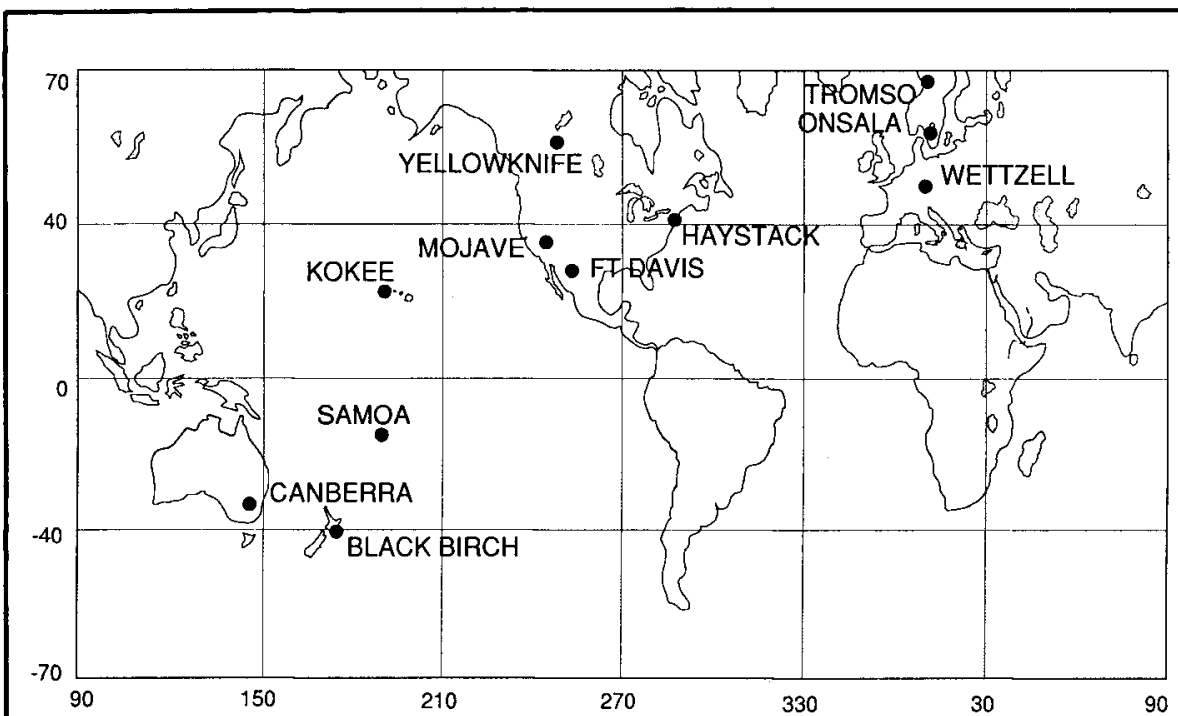

Fig. 1. Extended fiducial network for 1988 CASA UNO campaign.

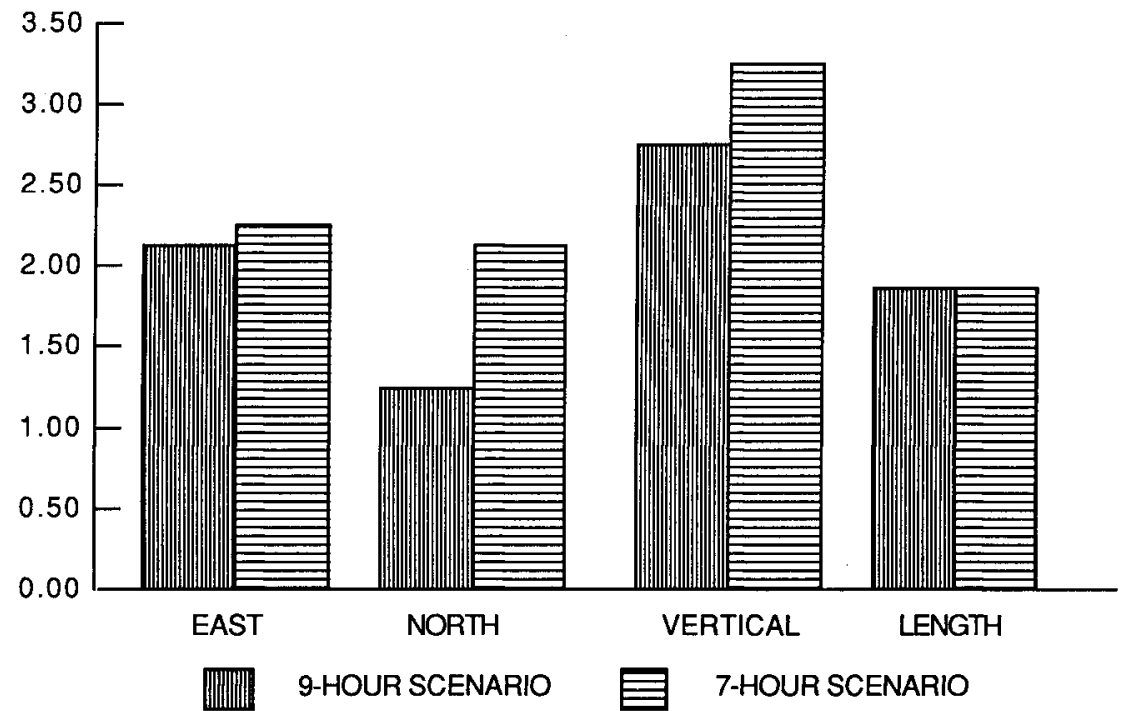

Fig. 2. Average of the consider baseline errors (in centimeters) from seven baselines in Central and South America. 
TI-4100 receivers and two new ROGUE receivers in Europe, North America, and the Pacific.

\section{Preliminary Results from 1988 CASA UNO Campaign}

The North Andean data have been transferred from cassettes onto 9-track magnetic tape and archived at JPL and at UNAVCO in Boulder, Colo. The data are available for distribution to all participants. Initial baselines are being calculated at JPL, the University of South Carolina (USC), Columbia, and Deutsches Geodatisches Forschungsinstitut (DGFI), Munich, West Germany. Preliminary precise satellite ephemerides have been calculated by the Center for Space Research, Austin, Tex. [Schutz et al., 1988].

Processing of the CASA UNO data set is an ongoing process and is expected to continue up until the second occupation. Data editing and calibration for the troposphere and ionosphere have been completed for most of the CASA UNO data set, including all the data from Central and South America, as well as four tracking stations in North America, two in Europe, two in the Pacific, and two in the Australia/New Zealand area. Two additional tracking stations at high northern latitudes have also been processed but have not yet been used because they suffered from extremely high ionospheric noise. Data recovery rates were better than $90 \%$ in South America, and about $75 \%$ in the worldwide tracking network.

Drewes et al. [1988] successfully used the Bernese software on the 1988 Venezuelan data. Using observational data from the CASA UNO campaign, they calculated a multistation solution for the Venezuelan network. After final cycle slip analysis and ambiguity resolution, they report an internal precision of about $5 \mathrm{~mm}$ on baselines of up to $200 \mathrm{~km}$ in length.

Although analysis of the CASA UNO GPS experiment is still in progress, preliminary re sults give some indication of the overall data quality. Although there are no methods to directly test baseline accuracy from this firsttime occupation, a good estimate of baseline precision can be obtained from the repeat ability of daily baseline solutions, assuming each day is treated independently. Previous results from southern California, where very long baseline interferometry measurements are available for comparison, suggest that GPS accuracy may be comparable to GPS pre cision [Blewitt et al., 1988; Dong and Bock, 1989]. Figure 3 illustrates the repeatability for 6 days of data for horizontal components of the $270-\mathrm{km}$ baseline from Limon to Liberia, Costa Rica [Kornreich et al., 1988]. Five days of data are plotted in Figure 4 for the 294-km baseline between Bogota and Cali, Colombia [Freymueller and Kellogg, 1988; Kel$\log$ et al., 1988]. These results were obtained using the GIPSY software developed at JPL Estimated parameters included satellite positions and velocities, station positions for sites in Central America, South America and Europe, carrier phase range ambiguities, and satellite and station clock biases modeled as white noise. The wet and dry zenith tropospheric path delay was modeled as a stochastic process [Tralli et al., 1988]. The positions of three sites in the U.S. were held fixed as

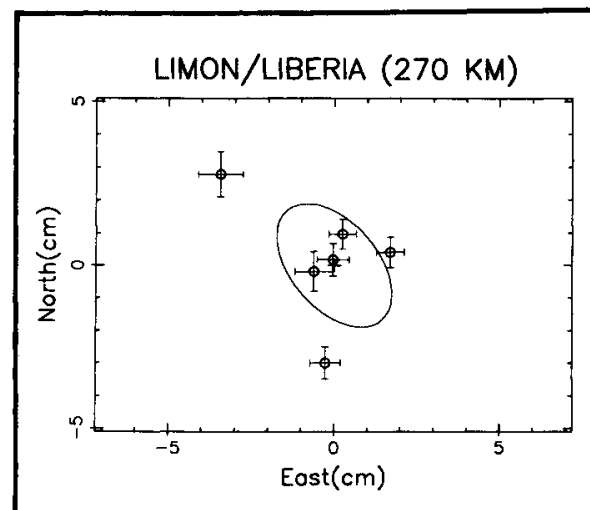

Fig. 3. Baseline component repeatabilities for the $270-\mathrm{km}$ Limon/Liberia baseline plotted with respect to their mean [Korm reich et al., 1988]. Error bars denote the formal errors (data noise). Ellipse represents 1 sigma error of the six independent daily solutions.

BOGOTA/CALI (294 KM)

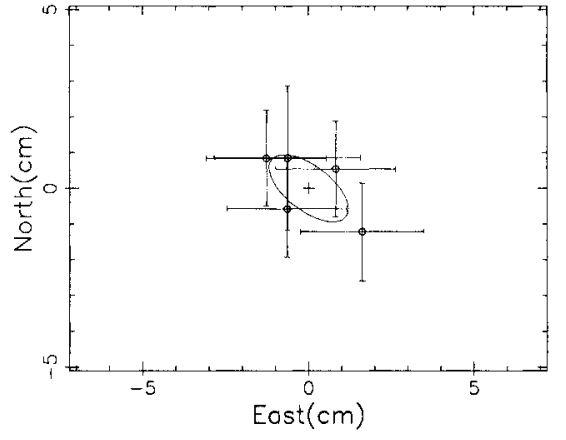

Fig. 4. Horizontal baseline solutions for the 294-km Bogota/Cali baseline plotted with respect to their mean [Freymueller and Kellogg, 1988]. Error bars and ellipse are the same as in Figure 3.

fiducial sites to establish a self-consistent reference frame and to constrain satellite ephemerides. Pseudorange data were used and carrier phase cycle ambiguities were fixed where possible [Blewitt, 1989]. Ninety five percent of the cycle ambiguities for the two Costa Rican sites, Limon and Liberia, were fixed successfully.

Repeatabilities of $1.5 \mathrm{~cm}$ for the length component and $2.3 \mathrm{~cm}$ for the vertical component were achieved on the Limon-Liberia baseline, while $0.7 \mathrm{~cm}$ in the length component and $4.6 \mathrm{~cm}$ in the vertical component were achieved on the Bogota-Cali baseline. This performance is comparable to the predictions made from covariance analyses prior to the experiment [Freymueller et al., 1986; Freymueller and Golombek, 1988]. Assuming that the accuracy of the final results is no worse than 1 part in $10^{7}$, this level of performance should be adequate to monitor expected plate velocities (up to $8 \mathrm{~cm} / \mathrm{yr}$ ) with 5 years of observations with an accuracy of better than $1 \mathrm{~cm} / \mathrm{yr}$. Analyses are in progress to test the effects of troposphere calibration, cycle ambiguity resolution techniques and various fiducial strategies. It is expected that these results will improve once fiducial stations from outside the U.S. are included in the analysis, and multiday arc and optimal bias-fixing strategies are employed.

The repeatabilities of daily baseline solutions suggest that adequate baseline accuracies can be obtained with the present satellite configuration. The CASA UNO collaborators, however, agreed to postpone the second campaign until January 1990 to insure an improved satellite constellation. Six Block II satellites are scheduled for launch in 1989. The enthusiasm shown by the 22 cooperating organizations from Latin America, North America, Europe, and the Pacific ensures continued international support for GPS geodesy in this tectonically active part of the world.

\section{Acknowledgments}

The authors wish to thank all the dedicated GPS field observers whose long nights in wet jungles, on cold Andean peaks, and on barren crab-covered rocks in the middle of the ocean made this successful experiment possible. These intrepid observers included J. Freymueller, D. Mucciarone, and W. Smith from USC; A. Bermudez, H. Canas, J. Cuellar, I. Daria Correa, M. Garzon, and C. Ropain from Instituto Nacional de Investigaciones Geologico-Mineras, Bogota, Colombia G. Urrea, V. Ramirez, L. Restrepo, P. Sandoval, and $C$. Velandia from Instituto Geografico Agustin Codazzi, Bogota; P. Burt, A. Jones, K. Marek, and J. Richardson from Inter American Geodetic Survey, San Antonio, Tex.; K. Clark, K. Gross, J. O'Brian, W. Prescott, R. Pritle, and J. Svarc from USGS, Menlo Park, Calif.; B. Stephens and J. Neilan from JPL; M. Jackson and J. Stowell from University NAVSTAR Consortium, Boulder, Colo.; E. Reiter from Massachusetts Institute of Technology, Cambridge; D. Johnson from University of Hawaii; J. Davidson and R. Morris from Canadian Geological Survey, Ottawa; G. Bailon and E. Ordanez from Instituto Geografico Militar, Quito, Ecuador; $H$ Drewes, K. Stuber, and H. Tremel from Deutsches Geodatisches Forschungsinstitut, Munich, West Germany; O. Chourio from Direccion de Cartografia Nacional, Caracas, Venezuela; H. Henneberg and M. Hoyer from Universidad del Zulia, Maracaibo, Venezuela; R. Merrell from Texas Highway Dept., J. Wells at the Deep Space Network site, Canberra, Australia; and J. Hannah from Department Surveys and Land Infor mation, New Zealand. We also would like to thank S. Dinardo, M. Cerezo, B. Stephens, T. Munson, M. Figueroa and the JPL shipping department for packaging and shipping the 8 tons of equipment. We also wish to thank $R$. Alvarado R. and R. Steer, Secretary Generals of Comision Colombiana de Oceanografia who arranged for transportation $500 \mathrm{~km}$ to and from Malpelo Island on Colombian naval vessels. We are very grateful for the cooperation of Colombian institutions in the experiment. INGEOMINAS (Director General A. Lobo-Guerrero-U.) and the Instituto Geografico (Subdirector Cartografia O. Nino) helped select 16 sites, monumented all the sites, provided 11 observers and all their air and ground expenses, and ground transportation for all observers, training, storage, and office space, and supervision of in-country logistics. The TI-4100 GPS receivers were supplied by the University NAVSTAR Consortium, Boulder, Colo., U.S. Defense Mapping Agency, Washington, D.C., U.S. Geological Survey, 
Menlo Park, Calif., U.S. Naval Oceanographic Office, Bay St. Louis, Statens Kartverk, Honefoss, Norway, Institute for Space Research of the Austrian Academy of Science, Point Mugu Naval Training Center, and the Canadian Geological Survey, Ottawa. WVR's were supplied by JPL. D. Diaz (USC) assisted with manuscript preparation. Support for the U.S. participants was from NASA, NSF grant EAR-8617485, University of South Carolina, and the University NAVSTAR Consortium.

\section{References}

Aggarwal, Y., Seismic slip rates and earthquakes rupture zones in the southern Caribbean: Implications for plate motions and earthquake hazard in this region (abstracts), Caribb. Geol. Conf., 10th, 16, 1983.

Berg, E., G. H. Sutton, and D. A. Walker Dynamic interaction of seismic activity along rising and sinking edges of plate boundaries, Tectonophysics, 39, 559, 1977.

Beutler, G., I. Bauersima, W. Gurtner, M. Rothacher, and T. Schildknecht, Evaluation of the 1984 Alaska Global Positioning System campaign with the Bernese GPS software, J. Geophys. Res., 92, 1295, 1987.

Blewitt, G., Carrier phase ambiguity resolution for the Global Positioning System applied to Geodetic Baselines up to $2000 \mathrm{~km}$, J. Geophys. Res., in press, 1989.

Blewitt, G., S. M. Lichten, P. M. Kroger, M. S. Kornreich, U. J. Lindqwister, L. L. Skrumeda, and W. I. Bertiger, Accuracy and long-term stability of GPS baseline estimates, Eos Trans. $A G U, 69,1151,1988$.

Bott, M. P. H., and D. S. Dean, Stress diffusion from plate boundaries, Nature, 243. $339,1973$.

Dewey, J. W., Seismicity and tectonics of Western Venezuela, Bull. Seismol. Soc. Am., $62,1711,1972$.

Dixon, T. H., M. P. Golombek, and C. L. Thornton, Constraints on Pacific plate kinematics and dynamics with Global Positioning System measurements, IEEE Trans. Geosci. Remote Sensing, GE-23, 491, 1985.

Dong, D., and Y. Bock, GPS network analysis with phase ambiguity resolution applied to crustal deformation studies in California, $J$. Geophys. Res., in press, 1989.

Drewes, H., O. Chourio, H. Henneberg, M. Hoyer, Ch. Reigber, S. Rekkedal, K. Stuber, and H. Tremel, The Venezuelan
Andes GPS-Network, IAG, Com. 8, Coordinat. Space Tech. Geod. Geodyn. Bull., Munich, 10, 103, 1988.

Freymueller, J. T., and M. P. Golombek, Geometry and treatment of fiducial networks: Effect on GPS baseline precision in South America, Geophys. Res. Lett., 15, 1467, 1988. Freymueller, J. T., and J. N. Kellogg, The effect of a global GPS tracking network on South American geodetic results, Eos Trans. $A G U, 69,1150,1988$.

Freymueller, J. T., J. N. Kellogg, and J.M. Davidson, GPS geodesy in the North Andes: Results of covariance analysis, Eos Trans. AGU, 67, 910, 1986.

Jordan, T., The present-day motions of the Caribbean plate, J. Geophys. Res., 80, 4433, 1975.

Kellogg, J. N., and W. E. Bonini, Subduction of the Caribbean plate and basement uplifts in the overriding South American plate, Tectomics, 1, 251, 1982

Kellogg, J., J. Freymueller, J. Stowell, T. Dix on, J. M. Protti, G. Gonzalez, C. Ropain, J Cuellar, and B. Fernandez, Preliminary 1988 "CASA UNO" GPS baselines for the North Andes, Eos Trans. AGU, 69, 1150, 1988.

Kellogg, J. N., I. J. Ogujiofor, and D. R. Kansakar, Cenozoic tectonics of the Panama and North Andes blocks, Mem. 6th Lat. Am. Geol. Congr. Bogota, 1, 40, 1985.

Kornreich, M. S., D. M. Tralli, T. H. Dixon, and J. N. Kellogg, Initial results from the CASA UNO Global Positioning Experiment: Tropospheric calibrations, Eos Trans. $A G U, 69,1323,1988$.

Ladd, J. W., M. Truchan, M. Talwani, P. L. Stoffa, P. Buhl, R. Houtz, A. Mauffret, and G. Westbrook, Seismic reflection profiles across the southern margin of the Caribbean, in Caribbean-South American Plate Boundary and Regional Tectonics, edited by W. E. Bonini, R. B. Hargraves, and R. Shagam, pp. 153-159, Geological Society of America, Boulder, Colo., 1984

Lehner, P., H. Doust, G. Bakker, P. Allenbach, and J. Gueneau, Active margins-Caribbean margin of South America, profiles C-1422, C-1412, and C-1413, in Seismic Expression of Structural Styles 3, edited by A. W. Bally, pp. 3.4.2-111-3.4.2-128, American Association of Petroleum Geologists, Tulsa, Okla., 1983.

Lu, R. S., and K. J. McMillen, Multichannel seismic survey of the Colombia Basin and adjacent margins, in Studies in Continental Margin Geology, edited by J. S. Watkins, S., and C. L. Drake, pp. 395-410, American Association of Petroleum Geologists, Tulsa, Okla., 1982.

Luschen, E., Recent tectonics of the Northern Andes according to geophysical and geodetic measurements in Colombia, Zentralbl. Geol. Palaontol., Teil I, 304, 1983.

Minster, J. B., and T. H. Jordan, Present day plate moions, J. Geophys. Res., 83, 5331, 1978.

Neilan, R. E., H. Cadess, M. Chin, T. H. Dixon, J. Hannah, J. Kellogg, W. Prescott, C. Reigber, J. Stowell, and B. Tallman, CASA UNO GPS-A summary of the January ' 88 campaign, Eos Trans. AGU, 69, 323, 1988.

Page, W. D., and M. E. James, The antiquity of the erosion surfaces and Late Cenozoic deposits near Medellin, Colombia: Implications to tectonics and erosion rates, Rev. CIAF, Bogota, Colombia, 6, 421, 1981.

Pennington, W. D., Subduction of the eastern Panama basin and the seismotectonics of northwestern South America, J. Geophys. Res., 86, 10,753, 1981.

Schubert, C., Late-Cenozoic pull-apart basins, Bocono fault zone, Venezuelan Andes, $J$. Struct. Geol., 2, 463, 1980.

Schutz, B. E., B. D. Tapley, C. S. Ho, H. J. Rim, and P. A. M. Abusali, GPS orbit determination: Experiments and results, Eos Trans. AGU, 69, 1149, 1988

Stein, S., and E. A. Okal, Seismicity and tectonics of the Ninety-East Ridge area: Evidence for internal deformation of the Indian plate, J. Geophys. Res., 83, 2233, 1978.

Tralli, D. M., and T. H. Dixon, A few parts in $10^{8}$ geodetic baseline repeatability in the Gulf of California using the Global Positioning System, Geophys. Res. Lett., 15, 353, 1988.

Tralli, D. M., T. H. Dixon, and S. A. Stephens, The effect of wet tropospheric path delays on the estimation of geodetic baselines in the Gulf of California using the Global Positioning System, J. Geophys. Res., $93,6545,1988$

Weissel, J. K., R. N. Anderson, and C. A. Geller, Deformation of the Indo-Australian plate, Nature, 287, 284, 1980.

Wu, S. C., W. G. Melbourne, T. P. Yunck, Impact of tracking network variation on GPS orbit determination, Pap. 88-0573, American Institute of Aeronautics and Astronautics, Reno, Nev., 1988. 